\title{
Relationship between intensity of fear and coping-strategies implemented by high-school and university students
}

\author{
Elena Romanova ${ }^{1, *}$ \\ ${ }^{1}$ Moscow State University of Civil Engineering, 26, Yaroslavskoye shosse, 129337, Moscow, Russia
}

\begin{abstract}
Fears warn and keep people away from threats to their lives and health. But sometimes fears are redundant and make people overcautious. Sense of fear is often driven by uncertainty or inability to control over the situation. The latter causes teenagers to worry and be afraid for health and possible negative outcomes of diseases of their loved ones as well as a need to carry responsibility also frightens them. The named fears prevail among the young generation in the beginning of the 21 st century. Copingstrategies help people to be in control of their phobias, stress and other triggers of anxiety. Current paper is devoted to finding connections between fears and coping-strategy to fight them. Low tension proves adaptive application of coping-strategies, while high tension signals about their maladaptive use. Maladaptive strategies do not adequately deal with the case and fail to cope with anxiety. The most stressful strategy for school and university students to take is «Accepting Responsibility». «Self-control» (for school students) and «Approach to problem solving» (for university students) are also on the list. Decrease in anxiety level is followed by using fewer high-tension coping strategies. Students may turn to their phobias as passive coping-strategies in cases when the known methods fail to take effect. Fear mobilizes defense mechanisms and supplementary resources to protect one from anxiety.
\end{abstract}

\section{Introduction}

Fear is one of the primary human emotions. It serves to alarm a person about a possible threat and mobilize one to react to the trigger.

Today, sense of fear is studied in three areas: molecular, cerebral and behavioral [1]. At the molecular level, the Gebb synaptic plasticity mechanism and the neuromodulatordependent mechanism are used to explain the process of gaining fear memory. Brain circuits that are responsible for identifying and managing fear are gradually revealed at the cerebral level. In event of a danger, brain immediately responds, sending signals, which activate the nerve system. This include the following body reaction as rapid heartbeat and breathing as well as elevation in blood pressure. Spasm of certain organs redirects blood flow towards muscles to mobilize the body to take action (such as running or fighting). The skin sweats to keep the body cool. This response is known as "fight-or-flight response".

*Corresponding author: romanova_e_v@mail.ru 
Sense of self-preservation instinctively prepares the body to either fend off an attack or to avoid one by running away. The body is in this state until the brain sends the signal "it is safe". After that, the physiological reactions of fear are turned off.

Our research is in the behavioral field, deriving from the Pavlov experiments. This approach examines the variety of fears and the ways of their manifestation, the social causes, the mechanisms and ways to overcome them, methods to correct anxiety behavior.

Healthy fear warns and keep a person away from threats to their lives and health. But sometimes fears are redundant and make people overcautious. Some are afraid to speak up in public: from an answer in front the class to holding a speech at a conference. Such fear is irrational since there is no real threat in it.

Having a lot of fears in childhood can be considered normal. Fear is a natural reaction in this age to feels of insecurity and vulnerability when a child faces new and unknown. According to research by Ruocco, S., Freeman, N.C., McLean, L.A. [2] the top five most common problems of primary school students included the following: fear of spiders (insects), fear of the dark and heights, being in an unfamiliar place without parents, poor school performance. As children grow up and gain life experience, with the support of adults, most of them gradually overcome these fears and outgrow them. Some children need more time, some less. If fears last longer than the expected age, it could be a sign of an anxious personality. However, in adolescence, new fears appear, which are related to the identity formation and the increased social activity of teenagers. The following fears prevail among secondary school students: fear of failure and criticism, fear of the unknown, fear of small injuries and small animals, fear of danger and death, and, finally, medical fears [3].

Formation of self-identity breeds a specific group of fears, like "cacomorphobia" (fear of overweight) [4], dysmorphophobia (fear of physical appearance defect) [5], dental fears [6], etc. Lacour, A.-G., Zdanowicz, N. [7] found that adolescents with IQ above 130 are more insecure and have more fears than their peers with lower IQ. Ueda, K. [8] pinpointed a tendency to increase with age «depressive state» that comes from the inability to overcome fears and phobias. He also mentioned the degrading of anxiety tolerance of adolescents in a person-to-person interaction.

Bouvard, M., Roulin, J.-L. [3] also note a change in the structure and intensity of fears compared to the end of the 20th century. With the advent of widespread information technologies, new types of fear have emerged, such as nomophobia (high fear of staying without a mobile phone) [9], cyberbullying [10].

To date, There has been accumulated a plenty of experience in tools for studying child and adolescent fears. The most well-known methods include Children's Depression Inventory (CDI), the Fear Survey Schedule for Children - Revised (FSSC-R) [11] the Children's Action Tendency Scale (CATS), Child Anxiety and Coping Interview (CACI) [2], Questionnaire on the hierarchical structure of actual fears of individuals (ISAS) Y.V. Shcherbatykh, E. Ivleva [12]. All of them are culturally conditioned and require adaptation to different groups of subjects.

Identifying fears is only a pocket of the behavioral approach. Technologies for overcoming fears and anxiety states are a more important part of it. These deliberate behavioral strategies that help a person cope with fear, stress, and other anxiety-generating events are commonly referred to as coping-behaviors or coping-strategies. Coping behavior mainly tackles with the following tasks: minimize the negative effects of the situation, adapt to the situation or transform it, maintain a positive "self-image" of emotional balance, maintain relationship with other people. Most children and adolescents, when anxiety and fear arise, develop their own coping strategies. They vary widely depending on gender, age and cultural background $[13,14]$. Yet they can all be divided into two groups: adaptive and non-adaptive. Adaptive strategies include self-control, seeking social support, taking responsibility, planning for problem solving, and positive revaluation. The non-adaptive 
ones are confrontation, avoidance and distancing. Specially organized help and support from specially trained psychologists is required in cases when a person uses predominantly non-adaptive strategies, or if the existing fears are too strong and prolonged. Examples of such counseling can be found in the work of Brouzos, A., Vassilopoulos, S.P., Vlachioti, A., Baourda, V. [15]: authors describe positive results of coping -wise group therapy of aide for adoloscents to tackle their anxiety, when moving to secondary school. Ruocco, S., Freeman, N.C., McLean, L.A. [16] experimentally demonstrated that 1-hour sessions of the cognitive-behavioral group training "Get Lost Mr Scary" helped young children to drastically decrease the use of non-adaptive strategies such as avoidance and to increase the application of adaptive cognitive strategies. McClain, C.M., Bolden, J., Elledge, L.C. [17] used the C.A.T. Project (teenage version of Coping Cat) to address anxiety disorders in cognitive-behavioral therapy. Ramírez-Fernández, C., Morán, A.L., García-Canseco, E., (...),Valenzuela, O., Hernández, N. [18] suggest using the haptic mobile augmented reality system TPAD and others for the treatment of fears of small animals in adolescents.

The goal of our research was to figure out connections between the fears of high-school and university students and the coping-strategies they apply.

As part of the study, the following objectives were set and accomplished:

- study the anxiety level and peculiarity of fears of Russian high-school and university students;

- find the preferable coping-strategies that students use to overcome their fears;

- figure out a connection between anxiety level and peculairities of coping-behavior.

The working hypothesis of the study: there is an inverse relation between the number of adaptive non-tense coping-strategies used by students and the level of anxiety; the more adaptive non-tense strategies are used, the less the intensity of the fears suffered.

\section{Methods}

Methods of theoretical analysis of scientific sources and documents, questionnaire methods, collection and statistical processing of empirical materials were used in order to accomplish the set objectives. Two psychological questionnaires were used to conduct the survey.

Questionnaire on the hierarchical structure of actual fears of individuals (ISAS) Y.V. Shcherbatykh is aimed to determine the intensity of fears and identify phobias. The subject must assess one's level of anxiety in 24 situations. A 10-point scale is used.

R. Lazarus questionnaire - Coping test (adapted by T.L. Kryukova, E.V. Kuftyak, M.S. Zamyshlyaeva) allows determining coping mechanisms, ways to overcome difficulties in various spheres of mental activity, coping strategies. The subject receives 50 statements describing behavior in a difficult life situation, and assesses how often their behavior coincides with that described in the situation.

The study was pulled off with two test groups. The first group consisted of high-school students aged 16-17. University students in the age of 19-20 were in the second group. During the study, all subjects were in rooms with similar physical conditions.

100 subjects answered the questions of the Lazarus questionnaire. 74 subjects answered the questions of the Scherbatykh questionnaire. 57 subjects answered the questions of both questionnaires.

\section{Results}

All of the tested students answered the ISAS questionnaire at the first stage. Comparative results of the intensity of fears among school and university students in relation to the standard indicator are shown in Figure 1. 


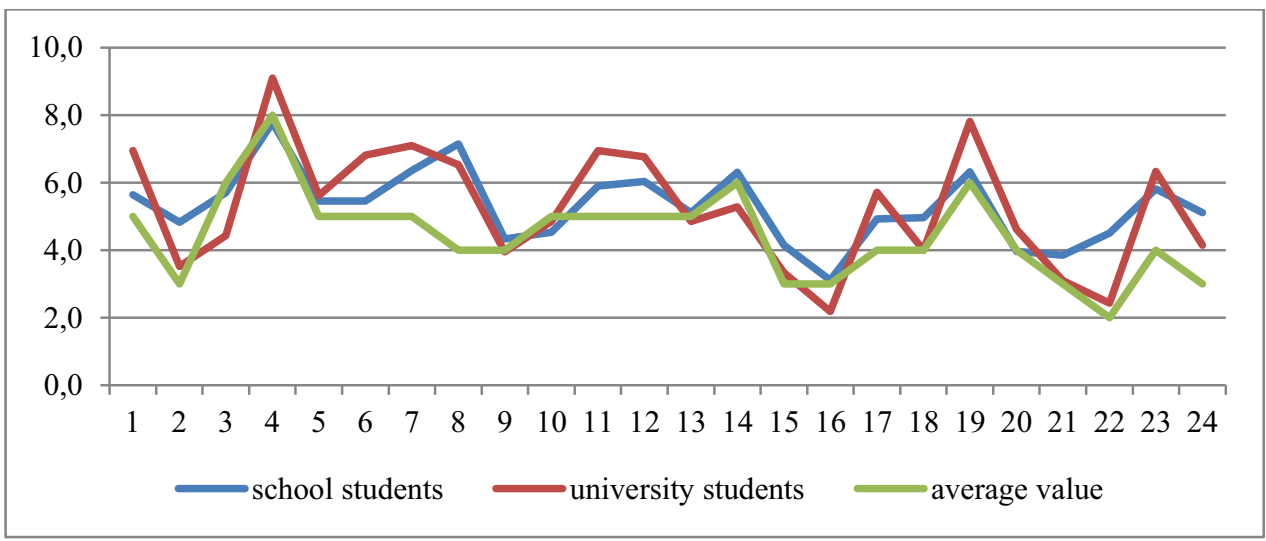

Fig. 1. Intensity of fears.

As it can be seen, in general, the intensity of fear experience (anxiety) of the subjects for most of the indicators is higher than the standard value (average) for ISAS in the group of healthy subjects (16-25 years old). The difference in the results of students from school and university was recognized as insignificant. Therefore, the results of all subjects are presented below in a common array.

Table 1 presents a quality analysis of anxiety experiences. The results demonstrate the number of subjects who rated the intensity of fear with a certain number of points.

Table 1. Distribution of quantitative assessment of fears.

\begin{tabular}{|c|c|c|c|c|c|c|c|c|c|c|c|}
\hline & \multirow{2}{*}{ Fears } & \multicolumn{10}{|c|}{ Score } \\
\hline & & 1 & 2 & 3 & 4 & 5 & 6 & 7 & 8 & 9 & 10 \\
\hline & & \multicolumn{10}{|c|}{ number of ticks (people) } \\
\hline 1 & Fear of spiders and snakes & 10 & 5 & 3 & 6 & 10 & 6 & 2 & 9 & 10 & 13 \\
\hline 2 & Fear of the dark & 13 & 11 & 14 & 7 & 4 & 3 & 4 & 10 & 1 & 7 \\
\hline 3 & Fear of madness & 11 & 7 & 8 & 6 & 12 & 4 & 3 & 3 & 7 & 13 \\
\hline 4 & Fear of illness of loved ones & 1 & 1 & 2 & 4 & 3 & 6 & 5 & 7 & 14 & 31 \\
\hline 5 & Fear of crime & 8 & 8 & 7 & 7 & 11 & 4 & 4 & 10 & 3 & 12 \\
\hline 6 & Fear of senior management & 11 & 3 & 9 & 4 & 5 & 9 & 5 & 7 & 8 & 13 \\
\hline 7 & Fear of changes in personal life & 8 & 2 & 6 & 2 & 10 & 2 & 6 & 15 & 6 & 17 \\
\hline 8 & Fear of responsibility & 1 & 5 & 6 & 3 & 5 & 8 & 8 & 10 & 14 & 14 \\
\hline 9 & Fear of aging & 19 & 8 & 8 & 9 & 5 & 9 & 3 & 4 & 4 & 5 \\
\hline 10 & Fear of developing heart diseases & 18 & 5 & 12 & 5 & 5 & 7 & 3 & 6 & 8 & 5 \\
\hline 11 & Fear of poverty & 7 & 1 & 8 & 7 & 6 & 5 & 8 & 15 & 8 & 9 \\
\hline 12 & Fear of future & 5 & 6 & 8 & 3 & 9 & 6 & 6 & 7 & 10 & 14 \\
\hline 13 & Fear of pain & 10 & 12 & 8 & 10 & 4 & 5 & 3 & 5 & 6 & 11 \\
\hline 14 & Fear of war & 9 & 4 & 6 & 2 & 12 & 5 & 6 & 12 & 6 & 12 \\
\hline 15 & Fear of death & 23 & 11 & 5 & 7 & 6 & 7 & 3 & 4 & 3 & 5 \\
\hline 16 & Fear of enclosed places & 37 & 10 & 5 & 5 & 4 & 4 & 1 & 6 & 0 & 2 \\
\hline 17 & Fear of heights & 16 & 7 & 4 & 11 & 1 & 6 & 4 & 9 & 6 & 10 \\
\hline 18 & Fear of depths & 20 & 7 & 7 & 5 & 4 & 8 & 6 & 1 & 6 & 10 \\
\hline 19 & $\begin{array}{l}\text { Fear of negative consequences of } \\
\text { diseases of loved ones }\end{array}$ & 6 & 4 & 5 & 2 & 5 & 9 & 3 & 15 & 8 & 17 \\
\hline 20 & Fear of falling ill & 22 & 6 & 5 & 12 & 7 & 6 & 3 & 5 & 2 & 6 \\
\hline 21 & Fear related to sexual function & 25 & 12 & 7 & 3 & 4 & 8 & 4 & 8 & 3 & 0 \\
\hline 22 & Fear of suicide & 28 & 10 & 6 & 3 & 4 & 3 & 4 & 6 & 2 & 8 \\
\hline 23 & Fear of public speaking & 7 & 4 & 6 & 8 & 10 & 7 & 5 & 7 & 7 & 13 \\
\hline 24 & $\begin{array}{l}\text { Fear of acts of aggression towards } \\
\text { loved ones }\end{array}$ & 20 & 7 & 5 & 6 & 6 & 5 & 3 & 5 & 6 & 11 \\
\hline
\end{tabular}


The cells with the results corresponding to the ISAS average are highlighted in dark color in the table. Results indicating phobic symptoms are in bold italics.

As it can be seen, school and university students most intensively suffer fear of illness of loved ones, fear of the negative consequences of disease of loved ones and fear of responsibility. The least worried are fears of enclosed places, fears of suicide and fears related to sexual function.

The author of the ISAS Shcherbatykh breaks fears into three groups: biological, social and existential. There is no strict division. We combined fears the following way:

- biological fears: fear of spiders and snakes, fear of developing heart diseases, fear of pain and fear of falling ill;

- social fears: fear of illness of loved ones, fear of crime, fear of senior management, fear of changes in personal life, fear of responsibility, fear of poverty, fear of war, fears related to sexual function, fear of public speaking, fear of acts of aggression towards loved ones;

- existential fears: fear of the dark, fear of madness, fear of aging, fear of future, fear of death, fear of enclosed places, fear of heights, fear of depths, fear of suicide.

Figure 2 demonstrate the comparison of fear intensity by groups (percentage of subjects from the total).

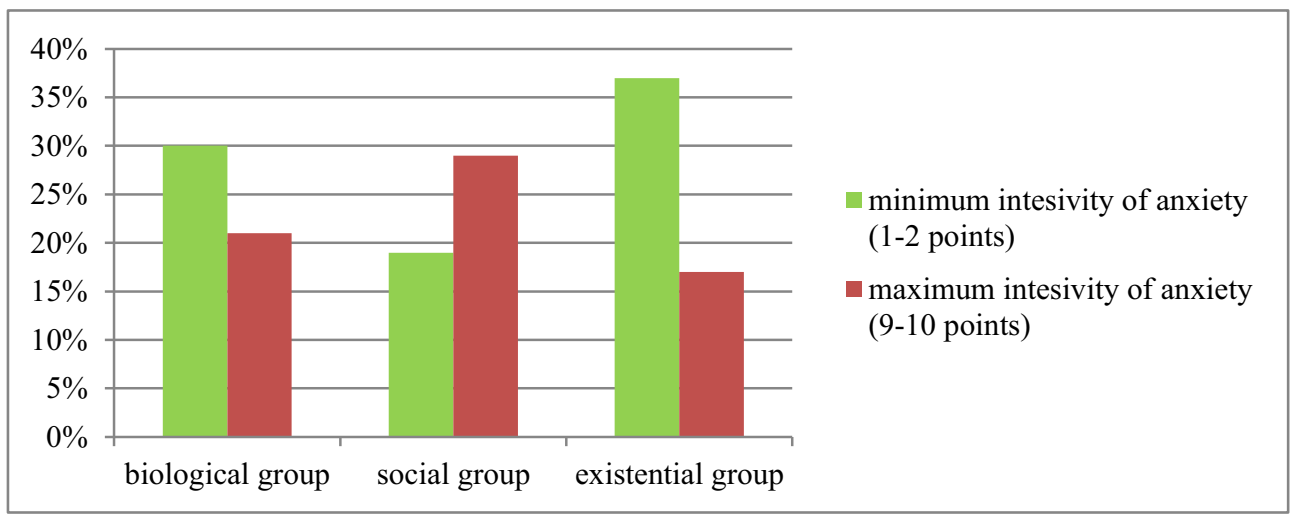

Fig. 2. Intensity of fears by groups.

As it can be seen, the largest number of intensely suffered fears belong to the social group. The most "fearless" results are to the fears of the existential group.

Coping strategies used by school and university students were studied at the second stage. Processing the results of the R. Lazarus questionnaire, it is important to take into account not only what strategies the subject uses, but also the degree of tension of each strategy. If the coping strategy is used in less than $33 \%$ of cases, then this is a low level of tension; this indicates adaptive coping. If coping is used in $33 \%-66 \%$ of cases, this signals that the adaptive potential of the individual is in a borderline state. The use of coping in $66 \%$ of cases and higher indicates a pronounced maladaptation. Figure 3 shows the summary results of the tension of coping strategies (C - confrontation, D - distancing, A avoidance, S - self-control, AR - accepting responsibility, PPS - planning problem solving, PR - positive revaluation, SSS - seeking social support). 


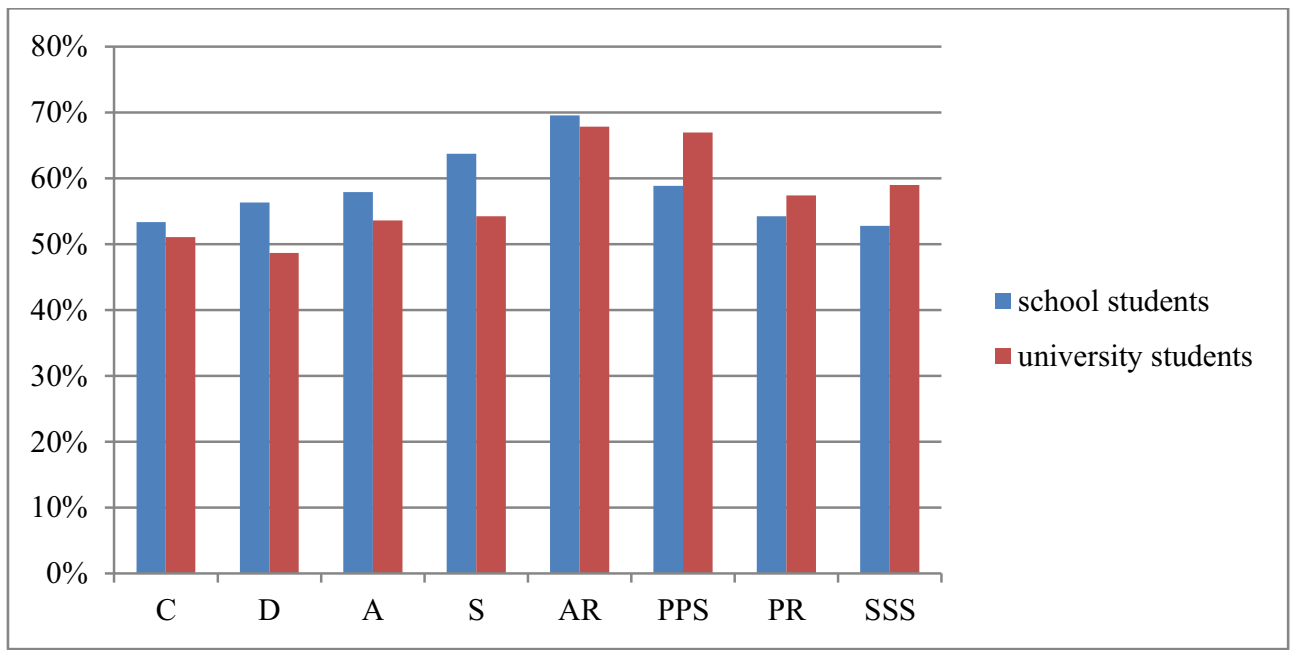

Fig. 3. Degree of tension of coping-strategies.

So, the most stressful for both groups of subjects is the strategy of "accepting responsibility". It is used in more than $66 \%$ of cases, which indicates its apparent maladaptation. Second most intense strategy diverges. It is «Self-control» for school students $(64 \%$ - in borderline state) and «Planning problem solving» is for university students (67\% - maladaptive tension). None of the strategies has a tension less than $33 \%$ (adaptive option). Non-adaptive coping strategies (confrontational coping, distancing, avoidance) are generally more intense in school students than in university ones.

Table 2 shows the ratio of the number of strategies used by students from school and university at the adaptive and maladaptive levels of tension.

Table 2. Adaptive and maladaptive application of coping-strategies.

\begin{tabular}{|l|r|r|r|r|r|r|r|r|r|r|}
\hline \multirow{2}{*}{ Test group } & \multicolumn{8}{|c|}{ Number of used strategies } \\
\cline { 2 - 9 } & $\mathbf{0}$ & $\mathbf{1}$ & $\mathbf{2}$ & $\mathbf{3}$ & $\mathbf{4}$ & $\mathbf{5}$ & $\mathbf{6}$ & $\mathbf{7}$ & $\mathbf{8}$ \\
\hline & \multicolumn{8}{|c|}{ adaptive level (<33\%) } \\
\hline $\begin{array}{l}\text { School } \\
\text { students }\end{array}$ & $48 \%$ & $\begin{array}{r}\text { school } \\
\text { students }\end{array}$ & $11 \%$ & $5 \%$ & $9 \%$ & $1 \%$ & $1 \%$ & $0 \%$ & $0 \%$ \\
\hline $\begin{array}{l}\text { university } \\
\text { students }\end{array}$ & $52 \%$ & $\begin{array}{r}\text { school } \\
\text { students }\end{array}$ & $19 \%$ & $0 \%$ & $5 \%$ & $0 \%$ & $0 \%$ & $0 \%$ & $0 \%$ \\
\hline & \multicolumn{8}{|c|}{ maladaptive level (> 66\%) } \\
\hline $\begin{array}{l}\text { School } \\
\text { students }\end{array}$ & $5 \%$ & $10 \%$ & $23 \%$ & $20 \%$ & $15 \%$ & $14 \%$ & $6 \%$ & $6 \%$ & $0 \%$ \\
\hline $\begin{array}{l}\text { university } \\
\text { students }\end{array}$ & $0 \%$ & $\begin{array}{r}\text { school } \\
\text { students }\end{array}$ & $19 \%$ & $14 \%$ & $29 \%$ & $5 \%$ & $0 \%$ & $5 \%$ & $5 \%$ \\
\hline
\end{tabular}

The third stage of the study was focused on finding a link between fears and coping strategies. Attempts to qualitatively compare the fears suffered by the subjects with the coping strategies they used failed to give results. No positive correlation was found between the types, intensity of suffered fears and the coping strategies. However, when comparing the number of high tension coping strategies used by the subjects and the general level of their anxiety, calculated as the sum of the intensities of all experienced fears, a certain pattern was found and demonstrated in Figure 4. 


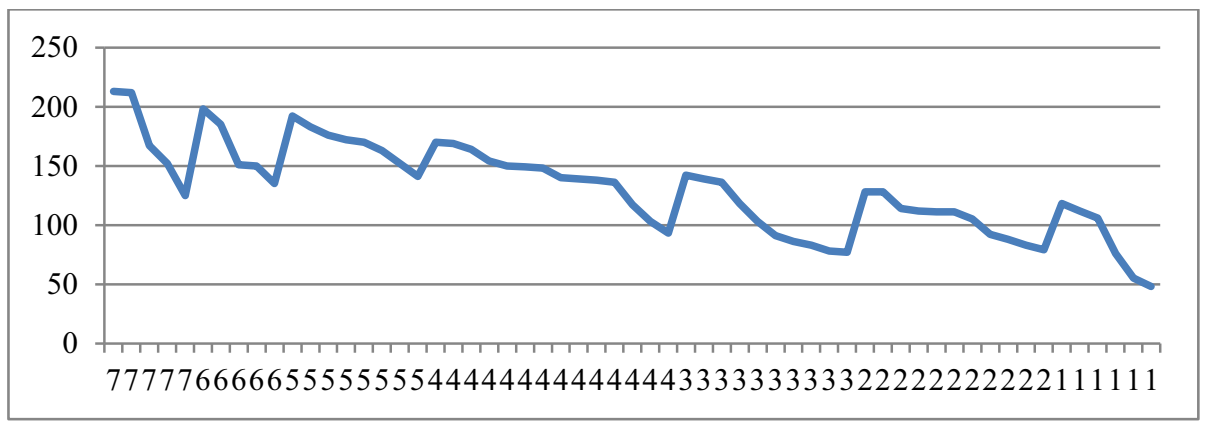

Fig. 4. The ratio of the number of applied tense coping strategies and the general level of anxiety.

The figure clearly shows the relation between the number of tension coping strategies used by the tested students (numbers on the horizontal axis) and their level of anxiety (numbers on the vertical axis): a decrease in the number of tension coping strategies is accompanied by a decrease in the anxiety level. Although, there is a high probability of an inverse cause and effect relationship: a decrease in the level of anxiety is followed with a decrease in the number of tense coping strategies applied.

A similar relationship between the intensity of fears and the use of non-tense coping strategies was not found (Figure 5.)

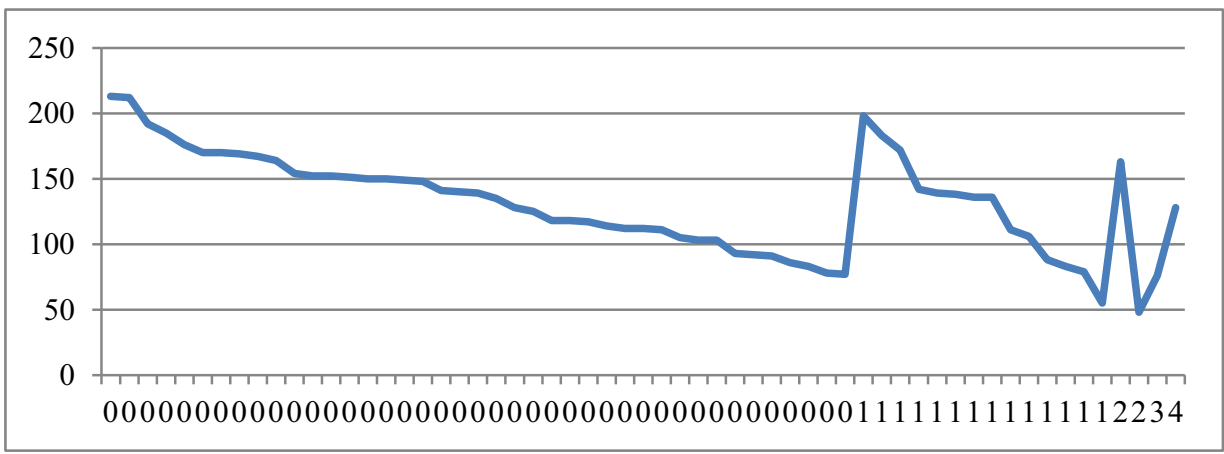

Fig. 5. The ratio of the number of applied non-tense coping strategies and the general level of anxiety.

\section{Discussions}

The results of the study showed that during the transition from school to university, the nature of a student's fears changes little. The fears of the social group remain the most suffered. And this is no coincidence. Adolescents go through a period of formation of selfidentity, determination of their position in society. On the one hand, they strive to make decisions on their own, manage their lives, dream of separating from their parents. On the other hand, they are still heavily dependent on loved ones financially and in everyday life, they cannot always cope by themselves even with their own problems, not to mention the problems of loved ones. Therefore, school and university students have a high intensity of fear for the health of their loved ones, for the negative consequences of their illnesses (which they, grown-up children, will probably have to solve), there is a great fear of responsibility, which more and more falls on their shoulders.

The higher results of the surveyed groups of students relative to the average standard values of the ISAS method should be especially noted. Most of the indicators exceed the norm by 1-3 points, which indicates the need to revise and adjust the standard values of this questionnaire. A similar idea is spoken in the work of Bouvard, M., Roulin, J.-L. [3], who 
experimentally demonstrated crucial differences in the studies of fear of children and adolescents in the 1980s and 2010s. In our study, the fear of responsibility is firmly second in the rating of fears, while it was only in 15 th place in the studies of Shcherbatykh Y.V. [12].

The fear of accepting responsibility paradoxically coincides with the coping strategy "Accepting responsibility", which is the most intense of all the strategies under consideration (70\% among school students and 68\% among university students). Highschool students and university students already highly evaluate importance and the significance of the decisions they make. Therefore, they take responsibility more often than it is necessary for adaptive behavior (although they are afraid of this responsibility). Since this strategy belongs to the adaptive group, its high tension does not aggravate the stressful situation, but does not prevent it either. The strategy «Planning problem solving» $(67 \%)$ was in second place among university students, «Self-control» was among school students (64\%). This is due to age-related changes in perception of reality. Adolescents are in a transition between childhood and adulthood. They need to control themselves in order to adapt to new requirements and standards, to be accepted in a new social group. Self-control helps them to restrain children's impulsive behavior, more carefully and consciously act in new situations, thereby relieving unnecessary anxiety from high demands and situations of uncertainty. University students have already left the school, what has changed their status in the view of society. It is not enough for them to harness their desires and merely observe life to develop themselves and build careers. Students are required to actively demonstrate their individuality, which is inevitably accompanied by new problems and difficulties, with which young people cope by exploiting the coping-strategy «Planning problem solving». Its tension also corresponds to the maladaptive level.

It is also noteworthy that university students demonstrate all three non-adaptive strategies (Confrontation, Avoidance and Distancing), although they are in a borderline state of tension, but have minimal values in comparison with the adaptive ones. Maladaptive strategies of school students are as tense as adaptive ones. This fact indicates that university students leave crisis adolescence and gradually master the adaptive strategies of coping behavior.

The found relationship between the level of anxiety and the number of tense copingstrategies used makes it possible to look at the fear suffered by the students as an additional coping-strategy. Similar data are found in the work of S.V. Gridneva, A.I. Tascheva [19], where the authors consider the demonstration of the emotion of fear by adolescents aged 910 years as a way of influencing adults and calling for help in moments of stress. In our opinion, fear may really act as a coping-strategy in situations when students do not have an adequate way to overcome stress, and all known methods failed. Suffering fear can cause a defensive reaction that mobilizes cognitive processes and lift a person out of a tense situation.

Thus, the hypothesis stated at the beginning of the study was not confirmed. However, a relationship between the intensity of fear and the number of applied coping-strategies was established. With a decrease in the anxiety level, a reduction in the number of tense copingstrategies is observed.

\section{Conclusions}

Fears are determined not only by age, personality traits, cultural norms, but also by the period of historical development. The fears of young people in the 20 s of the 21 st century differ from the fears of young people in the 80 s in their content with greater intensity and emphasis on the fear of responsibility. At the same time, the coping strategy «Accepting responsibility» gains high tension during the period of high school and university. Along 
with «Self-Control» and «Planning Problem Solving», these coping strategies are most actively used by young people to overcome difficulties and anxiety in situations of uncertainty during their transition to adulthood. Coping-strategies do not always give the desired effect of relieving anxiety due to their maladaptive high tension. The fear that arises in these cases can be viewed as a passive coping-strategy that mobilizes defensive mechanism of the body and thereby contributes to overcoming a difficult situation

\section{References}

1. Y. Chena, E3S Web of Conferences 131, 01007 (2019)

2. S. Ruocco, N.C. Freeman, L.A. McLean, Children Australia 43(4), 276-288 (2018)

3. M. Bouvard, J.-L. Roulin, Journal de Therapie Comportementale et Cognitive 22(1), 12-15 (2012)

4. N. Viernes, Z.A.J. Zaidan, A.S.S. Dorvlo, et al., Eating Behaviors 8(3), 407-417 (2007)

5. L. Goldsztaub, S. Dupont, Neuropsychiatrie de l'Enfance et de l'Adolescence 54(5), 304-314 (2006)

6. R. Bhola, R. Malhotra, Osong Public Health and Research Perspectives 5(4), 219-232 (2014)

7. A.-G. Lacour, N. Zdanowicz, Psychiatria Danubina 31, 386-389 (2019)

8. K. Ueda, Journal of the Osaka City Medical Center 52(1-2), 17-25 (2003)

9. I. Ramos-Soler, C. López-Sánchez, M.C. Quiles-Soler, Health and Addictions. Salud y Drogas 17(2), 201-213 (2017)

10. N.N. Chan, P. Ahrumugam, H. Scheithauer, A. Schultze-Krumbholz, P.B. Ooi, A hermeneutic phenomenological study of students' and school counsellors' "lived experiences" of cyberbullying and bullying (Computers and Education, 2020)

11. T.H. Ollendick, Behavior Research and Therapy 21, 685-692 (1983)

12. Y.V. Scherbatyhk, E.I. Ivleva, Psikhofiziologicheskiye i klinicheskiye aspekty strakha, trevogi i fobiy (Voronezh Istoki, 1998)

13. P.K. Jonason, D. Talbot, M.L. Cunningham, J. Chonody, Personality and Individual Differences 155, 109755 (2020)

14. J. Vaculíková, Turkish Online Journal of Educational Technology 04, 91-98 (2017)

15. A. Brouzos, S.P. Vassilopoulos, A. Vlachioti, V. Baourda, Psychology in the Schools 57(1), 31 (2020)

16. S. Ruocco, N.C. Freeman, L.A. McLean, Educational and Developmental Psychologist 35, 67-87 (2018)

17. C.M. McClain, J. Bolden, L.C. Elledge, Clinical Case Studies 18(6), 432-451 (2019)

18. C. Ramírez-Fernández, A.L. Morán, E. García-Canseco, et al., Lecture Notes in Computer Science (including subseries Lecture Notes in Artificial Intelligence and Lecture Notes in Bioinformatics) 10586 LNCS, 666-676 (2017)

19. S.V. Gridneva, A.I. Tascheva, Vestnik Novosibirskogo gosudarstvennogo universiteta. Seriya: Psikhologiya 3(1), 42-52 (2009) 